\title{
Los cambios en El Salvador
}

Se cree que nuestra sociedad se ha democratizado, que existe libertad de expresión, que El Salvador de ahora, en materia político-ideológica, no es ni la sombra de lo que fue en el pasado, que es mucho, pero mucho lo que se ha caminado. Se dice que nos hemos vuelto serios, maduros y tolerantes. Que las diferencias ideológicas ya no son motivo de escándalo o amenazas, mucho menos de cárcel, destierro, desaparición o muerte. Que personas de distinto signo político expresan sus opiniones en la prensa, la radio e, inclusive, en la televisión —el medio de las estrellas- sin ningún problema.

Se dice que la recién pasada campaña electoral demostró lo mucho que hemos avanzado en nuestra democratización. La oposición fue tan respetuosa de su adversario -el otrora Paquito Flores o "el brother", para sus allegados- que ni siquiera denunció la corrupción escandalosa del antiguo régimen, ya no digamos lo poco eficiente que había sido el segundo gobierno de ARENA, lidereado por el señor Calderón Sol que, sin lugar a dudas, compite en inteligencia con los ex presidentes del Partido de Conciliación Nacional: Molina y Sánchez Hernández y, seguramente, les gana.

El ahora, señor presidente, licenciado Flores, tampoco recurrió a la propaganda negra para vencer a "su adversario", el comprensivo Facundo. No hubo necesidad de hacerlo, los del Frente llegaron a la justa electoral derrotados. No obstante el hecho de que se no se haya acudido al fantasma del comunismo, no prueba que ya hayan abandonado tales prácticas heredadas de los gobiernos de conciliación. Porque lo que es "el tamal" de los secuestros lo tenían muy bien preparado para activarlo en el momento que fuera preciso, si no lo hicieron fue porque las encuestas les vaticinaban suficiente ventaja para ganar la presidencia en primera vuelta, mas no porque los areneros se hubieran convertido a la democracia.

Como parte de los cambios ocurridos en el país, el nuevo gobierno de ARENA montó fenomenal show para nombrar a los nuevos funcionarios pero, como dicen, más fue la bulla porque los puestos no hacen a las personas y si éstas son lo que son, pues no podrán transformarse por arte de magia en brillantes funcionarios. El gabinete está al nivel del presidente, con mucha aureola pero con muy poca obra realizada o con muy pocos productos conocidos. Pero el licenciado Flores se ha cuidado de que no se le vaya a confundir con un gobierno distinto a los típicos areneros, que él es un fiel heredero del mayor y para ello nos ofrece dos botones de muestra: el furibundo anti-comunista, anti-comunitarista, anti-efemelenista, antiliberacionista, anti-artista —sólo porque termina en "ista" y venían de Cuba- el ministro del interior Acosta Ortel y su compañero de hazañas el ex oreja, y otras hierbas, el nuevo director de la Policía Nacional Civil.

Tal parece que dentro de los cambios cosméticos de que hace gala nuestra guanancia tropical se encuentra la toma de posesión tipo cuento de hadas. Y siguiendo la ingenua fantasía tendríamos que el hijo del pastor llega a gobernante e invita a su amigo, el Príncipe, al acto solemne, al cual asiste además toda la corte luciendo sus mejores galas: sombreros y sacolas de color pastel, muy bien combinadas con carteras y zapatos de tacón, la o el encargado de sociales publica la crónica real en el matutino neoliberal, de señas conocido. Mientras la pobrería -espiritual y más de alguno material一, pero que tiene televisor, disfruta del acto en 
pantalla chica; los otros, los más pobres materialmente hablando, ni se enteran de lo que está pasando. Un nuevo presidente, ¿y qué? Que vino un príncipe amigo y otro por compromiso a su coronación. ¿Qué príncipe? ¿El que despertó a la Bella Durmiente? ¿Quiere decir que Sai Baba es príncipe, pues?

Aparte de lo anterior, una muestra que, según algunos, más que muestra es una prueba de los profundos cambios operados en el país, es el hecho de que muchos personajes de la izquierda política escriben en los periódicos y hablan en la radio y la televisión. Seguramente no existen razones para dudar de que esas personas sean, o hayan sido, de izquierda cuando menos, ya que regresaron al país luego de los "acuerdos de paz". El punto por discutir es si efectivamente existe o no apertura de parte de los propietarios de los medios de comunicación masiva, o si sencillamente se aprovechan de esas personas con imagen de izquierda. Aunque ya un poco descolorida, pero de izquierda al fin.

Sin embargo, los cambios de que tanto se habla, más parecen haberse operado en muchos de aquellos que en el pasado se decían de izquierda, quienes, ciertamente, mucho se cuidan de que se les vaya a considerar como "marxistas", "comunistas", "izquierdistas", etc. Ahora resulta que en El Salvador, el único que no ha cambiado es Shafik Handal; él es el único comunista, marxista-leninista, izquierdista y "dinosaurio" político - y de ajuste le añaden que es enojado porque protesta cuando le interrumpe más de algún ignorante presentador de televisión - porque no se deja manipular por parte de algún abusivo reportero-, en razón de que es el único diputado que se expresa en los medios de comunicación masiva como un auténtico político de izquierda.

Algunos de los columnistas de los dos matutinos nacionales pudieron haber sido muy de izquierda en la década pasada, pero sus planteamientos de ahora de tanta moderación, de tanta objetividad, de tanto pragmatismo, de tanta racionalidad que han buscado, ya no son problema para las censuras de los matutinos de marras y, en consecuencia, tampoco le sirven de mucho a las mayorías populares, cuyos intereses siguen siendo opuestos a los intereses de los ricos. Otros han cambiado sus temáticas y han encontrado que en la cotidianidad de la vida hay su- ficiente material para pasar entretenidos toda una eternidad, sin necesidad de entrar en conflicto con sus "protectores" o admiradores recién conseguidos. Para otros, el problema de su vivir con comodidad les obliga a ponerse en ocasiones hasta aduladores, por no llamarles "laméculos" y siendo así, no existe ningún problema en que se les publique cualquier cosa que escriban. Están los otros, los que no cambian, pero a éstos si acaso les publica el Co-Latino, pero jamás de los jamases uno de los llamados periódicos serios. Para éstos, o estás encuadrado dentro los principios básicos del sistema o no existís; si se te ocurre cuestionar el sistema, que no se te ocurra querer publicarlo porque lo único que podrías lograr es que ya no se te publique nada. ( $\mathrm{Si}$ no lo cree, alguno de los columnistas, puede hacer la prueba.)

Por todo lo anterior se puede afirmar que quienes han cambiado no han sido los retrógrados de derecha, sino los izquierdistas tibios. De manera que quienes persisten con un discurso coherente a favor de las mayorías populares, despiertan el odio, la intolerancia y toda la sed de sangre de aquellos que juraron que El Salvador sería la tumba de los rojos. Y ser rojo es estar a favor de los pobres y poco importa si se es campesino u obrero, cura o militar, arzobispo o doctor, trabajador manual o intelectual... Aunque estos últimos despierten más odio, ya que se dice que con su pluma envenenan la mente. Esto fue dicho recientemente en un canal de televisión. i"Y que no que había cambiado El Salvador"!

Reconozcamos que algo ha cambiado, además de los izquierdistas. Ya no hay guerra, por ejemplo, lo cual es bastante bueno en sí mismo, aunque

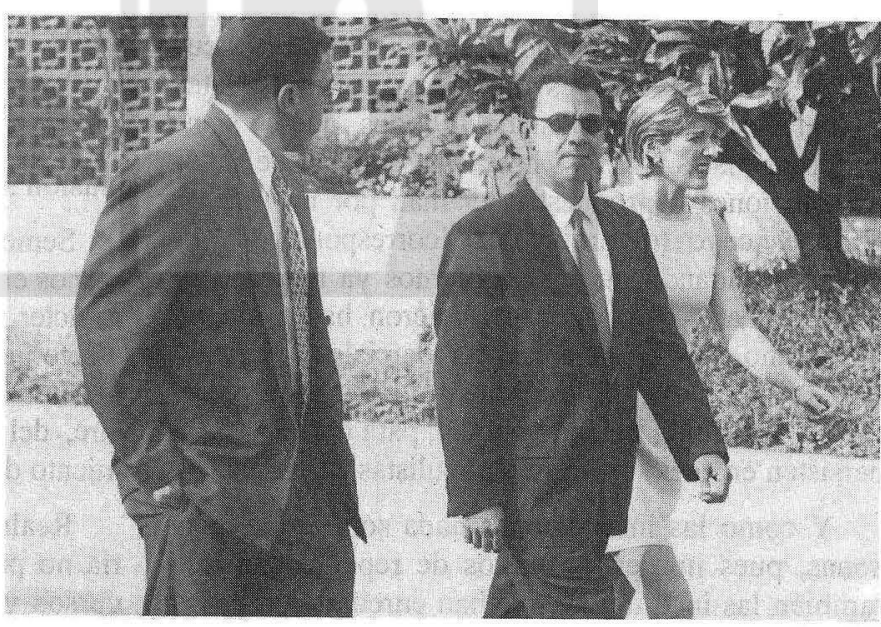


sigamos sufriendo con algunas de sus secuelas. Las muertes, los secuestros, los asaltos, los heridos, los robos, etc. abundan hoy más que antes. Cambio positivo es también que la democracia cristiana y los de conciliación vayan perdiendo presencia a nivel nacional. Poco a poco la gente se percata de sus negocios políticos, lo cual no es lo mismo que negociación política como ellos creen.

Cambio esperanzador fue que la izquierda política ganara muchas alcaldías y diputados y que se lo permitieran los areneros por despiste o prepotencia. Pero no pasó de ahí, para bien o para mal. Cambio triste, preocupante y desesperanzador es que las mayorías populares urbanas hayan perdido su organización, lo cual posibilita que se gobierne irrespetando sus intereses y violando sus derechos, sin que se tenga oposición ni resistencia... Y como corolario, ni siquiera se le pase la factura al gobierno en el momento electoral porque no hubo toma de conciencia. Los medios de comunicación masiva y sus comentaristas se encargan de encubrir la realidad de las cosas y de adormecer cualquier inquietud instintiva de los sectores populares.

En el agro, al haberse fusionado terratenientes y campesinos, burguesía agraria y obreros agrícolas, a causa de una línea política oportunista y electorera, el cambio ocurrido es que se ha desmovilizado a la organización campesina, la cual es real y fuerte. La izquierda política a causa de su moderación, apertura y concertación claudicante, ni siquiera ha logrado articular un proyecto propio y de beneficio para las mayorías populares rurales, las cuales cuentan con todos los elementos necesarios para ser un movimiento fuerte y de avanzada.

Pero lo peor de este maravilloso cambio ocurrido en El Salvador es que, ahora, algunos intelectuales educados en Estados Unidos, que se sienten progresistas y a ratos hasta con el deber de sugerir soluciones o propuestas, claman por un tipo de acciones cuyo rol protagónico corresponde al gobiemo, olvidando que los gobiernos ya tuvieron su turno al bate, pero que no pudieron hacer mucho porque no pueden dejar de ser parciales y cuando esto se les olvida, allí están los militares para recordarles para quien trabajan o, bien, para derrocarlos si persisten en acciones disque populistas.

Y como las instituciones nada son sin las personas, pues nos encontramos de repente con que también las instituciones se han enredado en y con los problemas de la cotidianidad. Se le dedica más tiempo y recursos a conocer qué opinan las personas sobre esto y aquello, que a conocer cuál es su situación real, su situación objetiva. Pero es que sólo hay recursos para conocer lo subjetivo, a los donantes no les importan las condiciones socioeconómicas de la población, dirá cualquiera a quien se le cuestione sobre el particular.

Y cuando una sociedad comienza a vivir de las opiniones es casi como decidir vivir de ilusiones, lo cual no resulta extraño en una sociedad consumista como ésta; lo preocupante es que nadie proteste, que todos acepten tranquilamente y que inclusive algunas instituciones de trayectoria crítica y contestataria terminen jugando el juego que han inventado los amos del sistema.

La realidad actual, dominada por la globalización del capital transnacional, genera dos graves problemas a nivel mundial: la exclusión social y la destrucción medio ambiental, ambos exigen de análisis, de conocimiento y de propuestas novedosas, ya que dejados a la suerte del mercado tenderán a incrementarse, a agravarse, lo cual es un mal para las mayorías populares de El Salvador y del mundo.

Cuando hablamos de la exclusión social estamos hablando de una realidad terrible e inédita, el mundo nunca había llegado en el sistema capitalista a una situación tal en la que de manera sistemática o estructural se dejara sin acceso a la vida social dentro del sistema a grandes contingentes poblacionales a nivel mundial. No estamos hablando de una crisis - aunque los efectos sean los mismos-, la cual se sabe que será pasajera, nos referimos a una tendencia que presenta el capital globalizado a excluir a las personas en todo el mundo, en algunos países con mayor profundidad que otros, pero ninguno está exento: tanto subdesarrollados como desarrollados sufren ya de la exclusión social y ésta tiende a incrementarse.

Semejante es el problema medio ambiental, al menos en cuanto a que muchos de sus efectos tienen carácter mundial; esto es obvio cuando se trata del efecto invernadero o de la ruptura de la capa de ozono. Localmente se puede sufrir la contaminación del aire, del agua, por ruido, etc. Así como el agotamiento del agua, de la tierra y la cobertura vegetal.

Realmente, al existir esta problemática tan seria no parece que tenga mucha lógica dedicar recursos y esfuerzos a las cotidianidades, más pro- 
pias de los columnistas de profesión. Pero gracias al cambio experimentado en El Salvador, quienes tienen capacidad de generar opinión, crítica y propositiva, se entretienen con la problemática de las multas a los transportistas, de la comupción, del "directo", de los políticos, de los procuradores, de los abusos en los recibos del celular, etc. Una problemática que presupone haber resuelto: el desem- pleo, el hambre, la carencia de vivienda, las desnutrición, las enfermedades infectocontagiosas, la destrucción del medio ambiente, la carencia de agua potable, esos que se denominan problemas de origen estructural y que padece la mayoría de la población.

Urfano Calles 